\title{
DOSSIER
}

\section{Universidades Populares y experiencias de extensión educativa en América Latina en la primera mitad del siglo $\mathrm{XX}$}

Las Universidades Populares, destinadas a la formación de obreros y artesanos en ámbitos tan diversos como la alfabetización, la formación política y ciudadana, la prevención sanitaria, las enseñanzas prácticas y profesionales o la difusión cultural, fueron instituciones que surgieron por toda América Latina en el primer tercio del siglo XX. Aunque contamos ya con estudios relevantes sobre algunas de estas iniciativas, el tema ha sido aún escasamente abordado por la investigación histórica.

El nacimiento de las Universidades Populares requiere para su correcta interpretación de un abordaje transnacional, todavía poco frecuente en la historiografía latinoamericana, particularmente en el campo de la Historia de la Educación, que sigue estando muy centrada en los estudios de carácter nacional, con escasas miradas de conjunto que trasciendan la mera yuxtaposición de casos locales o nacionales. En el tema de las Universidades Populares la necesidad de este enfoque continental no viene dada solo por la mera similitud de las experiencias surgidas en los distintos países latinoamericanos en la época, sino especialmente porque la gestación y el funcionamiento de estas iniciativas se desenvolvió dentro de un entramado de relaciones entre intelectuales de los más diversos países que propiciaron la circulación de ideas y experiencias, entre las que no faltaron tampoco las influencias europeas, en una época caracterizada por la conformación de una conciencia latinoamericana en el continente.

Sorprende que no contemos con un estudio más amplio y continental del fenómeno de las Universidades Populares latinoamericanas si 
tenemos en cuenta que la creación de estas instituciones suele relacionarse en exclusiva con las iniciativas de los movimientos estudiantiles y la llamada "extensión universitaria", que es quizás uno de los temas que la historiografía latinoamericana ha tratado con una perspectiva más continental. Esta visión latinoamericana del movimiento estudiantil fue posible, entre otras cosas, gracias al archivo documental recogido por Gabriel del Mazo sobre la repercusión en América Latina de la Reforma Universitaria de Córdoba de 1918, así como al trabajo pionero de José Carlos Portantiero sobre el movimiento estudiantil latinoamericano a partir de dicha reforma ${ }^{1}$. Las conmemoraciones de los $90 \mathrm{y}$ 100 años de la Reforma Universitaria de Córdoba han sido ocasiones para nuevas investigaciones que abarcan la órbita latinoamericana de los movimientos estudiantiles del primer tercio del siglo XX, entre los que destacamos el interesante trabajo coordinado por Martín Bergel, Los viajes latinoamericanos de la Reforma Universitaria (2018)².

No obstante, es necesario cuestionar la exclusiva adscripción de la creación de las Universidades Populares a las iniciativas del movimiento estudiantil y en particular a la Reforma Universitaria de Córdoba, pues ello no tiene en cuenta el protagonismo que tuvieron los propios obreros y sus organizaciones, los partidos políticos y "la intelectualidad extra-académica" en la creación de las Universidades Populares y otras instituciones dedicadas a la educación popular en muchos países de América Latina, algunas de ellas surgidas mucho antes de la Reforma Universitaria de 1918. Es preciso tener en cuenta igualmente que antes de dicha reforma se habían producido numerosas movilizaciones y congresos estudiantiles de repercusión continental en otros países de América Latina, en los que había empezado a cobrar una gran

1 Gabriel del Mazo (comp.), La Reforma Universitaria (Buenos Aires: Federación Universitaria de Buenos Aires, 1926-1927), 6 vols. En 1941 del Mazo publicó en el Centro de Estudiantes de Ingeniería de la Plata una compilación de documentos más breve, en 3 tomos. A partir de los documentos recogidos por del Mazo se hicieron otras compilaciones, entre las que destacamos la de Dardo Cúneo, La Reforma Universitaria, 1918-1930 (Caracas: Biblioteca Ayacucho, 1978). La obra de Juan Carlos Portantiero, Estudiantes y política en América Latina. El proceso de la Reforma Universitaria, 19181938 (México: Siglo XXI, 1978) incluye también una selección de documentos provenientes de la obra de Gabriel del Mazo.

2 Martín Bergel (coord.), Los viajes latinoamericanos de la reforma universitaria (Rosario: Humanidades y Artes Ediciones, 2018), 9.

3 Ricardo Melgar Bao, "Las Universidades Populares en América Latina, 1910-1925”, Estudios. Revista del Centro de Estudios Avanzados (Universidad Nacional de Córdoba) No. 11-12 (1999): 44. 
importancia la idea de la extensión universitaria ${ }^{4}$. Como afirma Agustín Cano Menoni, "la tendencia a una suerte de dieciochismo fundacional de numerosos estudiosos del tema, impide visualizar la riqueza de los procesos previos a 1918, las movilizaciones y los encuentros, las redes intelectuales y estudiantiles que se fueron tejiendo en esos años"

La creación de Universidades Populares en el primer tercio del siglo XX fue un fenómeno esencialmente urbano, que surgió en el proceso de crecimiento y modernización de las ciudades. Importantes sectores de artesanos y obreros, en algunos países engrosados por emigrantes extranjeros, serán los destinatarios y protagonistas de la acción de las Universidades Populares. También en esta época se produjeron experiencias de extensión cultural dirigidas al mundo rural, aunque mucho más escasas, a las que la historiografía de la educación ha prestado todavía muy poca atención. En este periodo fue México el único país de América Latina que a partir de su Revolución articuló el mundo urbano con el mundo rural. En algunos países de población indígena mayoritaria, donde no se llevaron a cabo reformas en el ámbito rural de la envergadura de las mexicanas, el indigenismo sería el discurso de una parte de los intelectuales críticos de la primera mitad del siglo XX, incluyendo iniciativas en el ámbito educativo que no consiguieron el impulso necesario para convertirse en reformas de hondo calado ${ }^{6}$.

Este dossier quiere ser una aportación a la discusión de ambas iniciativas de educación popular ${ }^{7}$, insistiendo en la necesidad de abordar

4 Mark van Aken, "University Reform before Córdoba", The Hispanic American Historical Review Vol. 51 No. 3 (1971): 447-462. Carlos Tünnerman afirma que el Movimiento de Córdoba fue "un movimiento latinoamericano que surgió en la Argentina, al darse allí una serie de factores que precipitaron su irrupción, y no una proyección latinoamericana de un fenómeno argentino". Carlos Tünnermann, "La reforma universitaria de Córdoba", Educación Superior y Sociedad, Vol. 9, No. 1 (1998): 114.

5 José Agustín Cano Menoni, "La extensión universitaria en la transformación de la Universidad latinoamericana del siglo XXI: disputas y desafíos", Documento de Trabajo (Buenos Aires: CLACSO, 2014), 2. También Alejandro Yaverovski reclama que la historia y el desenvolvimiento particular de las Universidades Populares han sido eclipsados por los sucesos de Córdoba de 1918. Alejandro Martín Yaverovski, "Cien años de oscuridad sobre las Universidades Populares: a cien años del chispazo de la Reforma Universitaria en Córdoba", Encuentro de Saberes No. 8 (2018): 23; Alejandro Martín Yaverovski, "Universidades Populares: la búsqueda de la genealogía propia", De Signos y Sentidos No. 19 (2018): 31.

6 El indigenismo es otro fenómeno transnacional que ha sido poco estudiado en sus efectos para la educación en la primera mitad del siglo XX.

7 Entenderemos aquí el concepto de educación popular en los términos que lo definen Jean-Louis 
su estudio desde una perspectiva continental. El dossier incluye, por una parte, el surgimiento de las Universidades Populares y la extensión universitaria, como fenómenos fundamentalmente urbanos y, por otra parte, las misiones pedagógicas y culturales destinadas a las poblaciones rurales.

\section{Algunos apuntes sobre el contexto}

Existe un consenso generalizado entre los historiadores al considerar el crecimiento de los sectores sociales medios como uno de los factores clave para explicar el contexto histórico en el que se desarrollan las iniciativas de educación popular que se abordan en este dossier. La ampliación de la participación política y las aspiraciones de los nuevos grupos emergentes en la primera mitad del siglo XX dieron lugar a un cuestionamiento de las formas políticas tradicionales y a un paulatino reconocimiento de los derechos sociales. En general, la cuestión social cobró relevancia como problema, al poner de relieve las consecuencias negativas que el desarrollo económico, la urbanización, los efectos de la Primera Guerra Mundial y la crisis del 29 causaban a la naciente clase trabajadora y a los sectores menos favorecidos de la sociedad. El socialismo, el anarquismo y otras ideologías de orientación popular fueron calando en las organizaciones de obreros y artesanos, así como en los intelectuales provenientes de la clase media, que se caracterizaron por su compromiso con los sectores populares. A su vez, desde las clases dirigentes se produjeron reacciones contra la amenaza que suponían las incipientes organizaciones y movilizaciones populares a las que se habían unido también los inmigrantes extranjeros que fueron llegando desde finales del siglo XIX sobre todo a países como Argentina, Uruguay o Brasil. Estas importantes tensiones fueron dando origen a paulatinas reformas sociales y políticas de diversa índole, así como a una

Guereña y Alejandro Tiana, como "el conjunto de los procesos que pretenden la educación de las clases populares (o grupos sociales dominados, subalternos e instrumentales de toda sociedad, recogiendo la expresión gramsciana) -jóvenes no escolarizados en el circuito escolar, adultos no alfabetizados o deseando un complemento de formación-, realizados fuera -o paralelamente- de los circuitos y procesos escolares". Jean-Louis Guereña y Alejandro Tiana, "La educación popular", en Historia de la Educación en la España Contemporánea. Diez años de investigación, eds. Jean-Louis Guereña, Julio Ruiz Berrio y Alejandro Tiana Ferrer (Madrid: Centro de Publicaciones del Ministerio de Educación y Ciencia, C.I.D.E., 1994), 142. 
progresiva intervención por parte de los Estados en distintos aspectos de la vida de las sociedades ${ }^{8}$.

Las clases medias emergentes fueron también protagonistas de una intensa efervescencia cultural y política de marcado carácter crítico ${ }^{9}$. Se creó todo un movimiento de reacción frente al auge de los valores utilitaristas del mundo anglosajón, afirmándose una conciencia latinoamericana que, por una parte significó una ruptura con la fuerte impronta positivista que había caracterizado al pensamiento del último cuarto del siglo XIX, haciendo un llamado a la juventud americana para representar otros valores espirituales (arielismo) ${ }^{10} \mathrm{y}$, por otra parte, reivindicó la potencia del mestizaje como síntesis de la conciencia latinoamericana ${ }^{11}$. La apelación a los valores espirituales de la juventud vinculó estas ideas al movimiento estudiantil, pero trascendió también su carácter intelectual para dar lugar a un extenso movimiento político continental que llamó a la unidad latinoamericana frente al imperialismo. Este discurso latinoamericanista crítico estuvo influido por otros movimientos internacionalistas originados en la Revolución Soviética y la Revolución Mexicana, y estuvo en la base de distintas formas de oposición y resistencia frente a los regímenes autoritarios que se instalaron en muchos países desde mediados de la década de 1910.

Los intensos contactos y la circulación de ideas que se produjeron entre intelectuales y líderes políticos del continente a través de congresos estudiantiles, viajes, intercambios de experiencias y publicaciones perió-

8 La Iglesia Católica, amparada en la encíclica Rerum Novarum de 1891, participó también de esta preocupación por las consecuencias negativas de las transformaciones sociales sobre las clases populares, y reaccionó ante las amenazas que se ceñían sobre la religiosidad de los obreros. La creación de los llamados "círculos obreros", así como diversas experiencias de educación dirigidas a las clases populares urbanas y a los indígenas, fueron algunas de sus iniciativas. Esta acción de la Iglesia católica en el terreno de la educación apenas ha sido estudiada en América Latina.

9 Esta efervescencia es un signo del cambio a una nueva fase cultural que Gregorio Weinberg describió como el paso de una cultura "aceptada" o "admitida", a una cultura "criticada" o "discutida". Gregorio Weinberg, Tiempo, destiempo y contratiempo (Buenos Aires: Ed. Leviatán, 1993), 48-55.

10 Esta corriente debe su nombre a la obra Ariel (1900), del pensador uruguayo José Enrique Rodó, que tuvo una amplísima difusión en América Latina. Otro pensador relevante dentro de esta corriente fue Pedro Henríquez Ureña, quien tendría un importante protagonismo en la gestación de la Universidad Popular Mexicana. Ver Liliana Weinberg, "Pedro Henríquez Ureña y las ideas de la Reforma Universitaria: tesis sobre la Universidad”, Cuadernos Americanos No. 167 (2019): 71-101.

11 El mexicano José Vasconcelos, que tendría una importante influencia sobre el movimiento estudiantil latinoamericano, reivindicó en su Raza Cósmica (1925) la potencia del mestizaje como síntesis de la conciencia latinoamericana (por la raza bablará mi espíritu). 
dicas suponen un giro trascendental en la vida política e intelectual de las naciones latinoamericanas en este periodo. Revistas de proyección y circulación continental como Repertorio Americano, dirigida desde 1919 por el costarricense Joaquín García Monge, o Amauta, fundada en 1926 por el peruano José Carlos Mariátegui, dan buena cuenta de la intensa red latinoamericana que se gestó en la primera mitad del siglo $\mathrm{XX}$, que tuvo también muy ricas manifestaciones en la literatura y las vanguardias artísticas. En general, la publicación de revistas vinculadas a los movimientos intelectuales y estudiantiles fue un fenómeno muy característico en cada uno de los países latinoamericanos en esta época, muchas de las cuales también tuvieron circulación internacional. Todas estas publicaciones periódicas constituyen quizás las fuentes más importantes para el estudio de la historia intelectual latinoamericana de la primera mitad del siglo XX, y ofrecen información imprescindible para el conocimiento de las iniciativas de los movimientos y asociaciones estudiantiles a favor de la educación popular ${ }^{12}$.

Como parte del escenario en el que se desenvolvieron las primeras Universidades Populares es importante destacar también la expansión de los sistemas educativos que se llevó a cabo sobre todo en las ciudades, convirtiendo a los sectores medios en sus principales beneficiarios. La sociología histórica ha afirmado que en América Latina la educación pública entre el último cuarto del siglo XIX y las primeras décadas del siglo XX fue precisamente uno de los factores importantes para la formación de las clases medias, ya que uno de los atributos que las definieron fue precisamente la educación ${ }^{13}$. La educación se convirtió, en efecto, en un factor clave en la dinámica de la movilidad social que se aceleró en este periodo, por lo cual las clases medias presionaron para ampliar su acceso a la enseñanza secundaria y superior. A su vez, los sistemas educativos desarrollaron estrategias para responder a las múltiples demandas de la llamada cuestión social, ampliando la función eminentemente política de integración nacional que venían cumpliendo los sistemas escolares desde el siglo XIX. Algunas manifestaciones de

12 Vid. Liliana Weinberg, "Redes intelectuales y redes textuales: las revistas del Reformismo Universitario", Revista de Historia de América No. 158 (2020): 191-221, así como Alexandra Pita González (comp.), Redes intelectuales transnacionales en América Latina durante la entreguerra (México: Universidad de Colima y Miguel Ángel Porrúa, 2016).

13 Vid. Ronn F. Pineo y James A. Baer (eds.), Cities of Hope. People, Protests and Progress in Urbanizing Latin America, 1870-1930 (Boulder, Colorado / Oxford: Westview Press, 1998), 263. 
esta preocupación social fueron, por ejemplo, el auge de la higiene como disciplina en el currículo escolar, y el surgimiento de discursos sociales acerca de la infancia ${ }^{14}$.

\section{Las Primeras Universidades Populares}

Es en la coyuntura de crecimiento y modernización de las ciudades, en las que habían surgido nuevos grupos sociales, donde vemos surgir a inicios del siglo XX las primeras Universidades Populares y otras iniciativas de educación popular en muchos países. Un ejemplo lo constituyen las primeras Universidades Populares de Buenos Aires ${ }^{15}$, que describe Alejandro Yaverovski en su artículo incluido en este dossier. Estas Universidades Populares surgen muy pronto por iniciativa de intelectuales y obreros vinculados al socialismo y al radicalismo, contribuyendo a su vez con su creación a forjar una peculiar identidad a los barrios bonaerenses donde se instalaron, en un momento de plena expansión de la ciudad.

Numerosos estudios de Historia Social y de Historia de la Educación han dado cuenta de la existencia de una serie de propuestas de educación popular que se impulsaron en Argentina desde finales del siglo XIX, tanto desde el Estado como desde el propio movimiento obrero. Experiencias similares surgieron también en otros países latinoamericanos en la época ${ }^{16}$.

14 Algunas investigaciones de gran interés sobre esta temática son las de Sandra Carli, Niñez, pedagogía y política. Transformaciones de los discursos acerca de la infancia en la historia de la educación argentina entre 1880 y 1955 (Buenos Aires: Universidad de Buenos Aires / Ed. Miño y Dávila, 2002); Javier Sáenz Obregón et al., Mirar la infancia: pedagogía, moral y modernidad en Colombia, 19031946. (Medellín: Colciencias / Eds. Foro Nacional por Colombia / Eds. Uniandes / Ed. Universidad de Antioquia, 1997, 2 vols.); Sonia Fernández Rueda, La escuela que redime. Maestros, infancia escolarizada y pedagogía en Ecuador, 1925-1948 (Quito: Corporación Editorial Nacional, 2018).

15 Alejandro Martín Yaverovski, "Tres Repúblicas Barriales y sus Universidades. Las Universidades Populares en la ciudad de Buenos Aires en el período de entreguerras: un esquema preliminar", Historia Caribe Vol. XVI No. 38 (Enero-Junio 2021): 35-79. DOI: https://doi.org/10.15648/ hc.38.2021.2817

16 El caso argentino es sin lugar a dudas un caso paradigmático, por el crecimiento más temprano de la clase obrera que se dio en este país, acrecentada por la inmigración europea. Pueden encontrarse numerosas referencias bibliográficas sobre diversas iniciativas de educación popular en Argentina en el artículo de Teresa Artieda incluido en este dossier. 
Como ejemplo del interés y la actividad que existía en Argentina en torno a la educación popular merece la pena mencionar el viaje que en 1909 realizó el profesor de la Universidad de Oviedo Rafael Altamira a ese país, donde suscitó enorme interés el modelo de la extensión universitaria de su Universidad, que Altamira presentó ante muy diversos auditorios, como sedes sindicales, sociedades docentes, pero también ante agrupaciones estudiantiles y Universidades. En octubre de 1909 Altamira incluso llegó a pronunciar en Buenos Aires la conferencia inaugural de un Congreso de Sociedades Populares de Educación, foro que convocó a sesenta y seis instituciones educativas populares ${ }^{17}$.

Otras Universidades Populares surgieron en otros países en los primeros años del siglo XX, como es el caso de México, donde los intelectuales que crearon en 1909 el Ateneo de la Juventud (luego Ateneo de México) fundaron ya en 1912 la Universidad Popular Mexicana, en la que se dictaron conferencias y cursos para obreros y que permaneció activa hasta $1920^{18}$.

En San José de Costa Rica se llevó a cabo una iniciativa de similares características con la creación en 1912 del Centro de Estudios Sociales Germinal por parte de un grupo de intelectuales y obreros, en el que participó Joaquín García Monge, fundador de la revista Repertorio Americano antes citada. Esta iniciativa, de fuerte influencia anarquista, tuvo como finalidad instruir a los obreros y divulgar ideas sociales. Aunque tuvo una corta duración, hacia 1926 una parte de estos intelectuales fundaría la Universidad Popular de Costa Rica ${ }^{19}$.

17 En ese mismo mes la Asociación Patriótica Estudiantil de La Plata fundó, siguiendo el modelo de la extensión universitaria de la Universidad de Oviedo, una Universidad Popular de breve existencia (es la más antigua vinculada a una Universidad de las que tenemos noticia). Gustavo H. Prado, Rafael Altamira en América (1909-1910). Historia e historiografía del proyecto americanista de la Universidad de Oviedo (Madrid: Consejo Superior de Investigaciones Científicas, 2008), 244-251.

18 En esta iniciativa participaron intelectuales de la talla de Antonio Caso, Alfonso Reyes o Pedro Henríquez Ureña. Vid. Morelos Torres Aguilar, Cultura y Revolución. La Universidad Popular Mexicana (México: UNAM, 2010). También en México la visita del profesor español Rafael Altamira en 1909 resultó un estímulo importante para la fundación de esta Universidad Popular. Vid. Liliana Weinberg, "Pedro Henríquez Ureña y las ideas de la Reforma Universitaria...", 86. tualidad en Costa Rica, 1900-1914 (San José: Acracia Editores, 2012); Vladimir de la Cruz, Las luchas sociales en Costa Rica, 1870-1930 (San José: Editorial de la Universidad de Costa Rica, 2004). 
El estudio conjunto en el ámbito de América Latina de este tipo de instituciones de educación popular cuya creación fue anterior a la Reforma Universitaria de Córdoba y cuyos promotores no estuvieron vinculados al mundo universitario, es una tarea aún pendiente.

\section{Universidades Populares y movimiento estudiantiL}

El movimiento estudiantil tuvo en América Latina una enorme relevancia en el origen de las Universidades Populares, como consecuencia de la idea de la solidaridad obrero-estudiantil y el compromiso social de la Universidad que caracterizó al discurso político y estudiantil de las primeras décadas del siglo XX, al que se sumó el tópico de la solidaridad continental latinoamerican ${ }^{20}$. La inquietud por extender los beneficios de la cultura a las clases populares aparece ya, mucho antes de la Reforma de Córdoba, en el Primer Congreso Internacional de Estudiantes Americanos de 1908 en Montevideo, así como en los dos siguientes Congresos de Estudiantes Americanos realizados en Buenos Aires (1910) y Lima (1912) ${ }^{21}$. La creación de centros universitarios y federaciones de estudiantes, como puede verse en el ejemplo del caso uruguayo abordado por Gabriel Scagliola ${ }^{22}$ en este mismo dossier, fueron ocasión para la puesta en marcha de numerosas actividades de extensión, entre las que se dio especial importancia a la educación higiénica, la lucha contra el alcoholismo y otras cuestiones que afectaban a las condiciones de vida de los obreros ${ }^{23}$.

A partir de la Reforma Universitaria de Córdoba de 1918, que dio un importantísimo estímulo a las organizaciones y movilizaciones estudian-

20 Eduardo Rinesi, "Prólogo", en Estudiantes y Política en América Latina. El proceso de la Reforma Universitaria, 1918-1938, ed. Juan Carlos Portantiero (Buenos Aires, Ed. de la Facultad de Filosofía y Letras de la UBA, 2018), 17.

21 También en Uruguay, Chile, Perú y Cuba las conferencias del profesor Rafael Altamira entre 1909 y 1910 demostraron que en los círculos universitarios existía un gran interés por la extensión universitaria. Gustavo H. Prado, "El compromiso de Rafael Altamira con la extensión universitaria ovetense y su difusión en América", Canelobre: Revista del Instituto Alicantino de Cultura Juan Gil-Albert No. 59 (2012): 87-88.

22 Gabriel Scagliola, "Las Universidades Populares en Uruguay (1930-1942)", Historia Caribe Vol. XVI No. 38 (Enero-Junio 2021): 81-105. DOI: https://doi.org/10.15648/hc.38.2021.2812

23 Véase también Daniel Omar de Lucía, "La tradición laica en la 'ciudad universitaria'. El movimiento librepensador en La Plata, 1896-1916”, en La Universidad de La Plata y el movimiento estudiantil, desde sus orígenes hasta 1930, comp. Hugo Biagini (La Plata: Editorial de la Universidad Nacional de La Plata, 2001), 20. 
tiles en el resto de América Latina, se reafirmó el lema de la extensión universitaria, reconociendo "que la Universidad necesita desenvolver, en la dinámica social, una función superior a la simple tarea periódica de patentar doctores[...] Ya que el pueblo no va hacia la Universidad, esta, representada por sus órganos positivos, irá hacia el pueblo, procurando llenar su verdadera misión de docencia social" 24 .

Pero fue quizás el Primer Congreso Internacional de Estudiantes, reunido en 1921 en México, el que dio un mayor impulso a la idea de la misión social de la Universidad. Entre sus resoluciones se incluía categóricamente que "es una obligación de los estudiantes el establecimiento de universidades populares, que estén libres de todo espíritu dogmático y partidista y que intervengan en los conflictos obreros inspirando su acción en los modernos postulados de justicia social"25. El impacto de los postulados de este Congreso para la creación de Universidades Populares en muchos países de América Latina se ejemplifica en el trabajo de Leticia González ${ }^{26}$ sobre la Universidad Popular de Guatemala incluido en este dossier. Uno de los fundadores de esta Universidad Popular en 1922 fue Miguel Ángel Asturias, que había sido uno de los tres representantes guatemaltecos en aquel Congreso ${ }^{27}$.

Como es sabido, la Reforma Universitaria de Córdoba tuvo en algunos países de América Latina un mayor impacto político, ya que en ellos el movimiento estudiantil consiguió crear alternativas políticas revolucionarias, como fue el caso del Perú, donde dio origen a la Alianza Popular Revolucionaria Americana (APRA) liderada por Víctor Raúl Haya de la Torre, o el caso de Cuba, donde uno de sus principales

24 "Manifiesto del Centro de Estudiantes de Derecho de Buenos Aires, al inaugurarse los cursos de extensión universitaria, agosto de 1920", en La Reforma Universitaria, 1918-1930, comp. Dardo Cúneo (Caracas: Biblioteca Ayacucho, 1978), 24.

25 Vid. Fabio Moraga Valle, "Reforma desde el sur, revolución desde el norte. El Primer Congreso Internacional de Estudiantes de 1921", Estudios de Historia Moderna y Contemporánea de México No. 47 (2014): 180.

26 Leticia González Sandoval, "Los estudiantes universitarios guatemaltecos y su proyección social: la Universidad Popular (1923-1932)", Historia Caribe Vol. XVI No. 38 (Enero-Junio 2021): 137-165. DOI: https://doi.org/10.15648/hc.38.2021.2814

27 En contraposición a la impronta latinoamericanista que impregnó al movimiento estudiantil y a las Universidades Populares, que tanto alentó José Vasconcelos desde México, convendría estudiar la creación de otras redes estudiantiles promovidas por los Estados Unidos, que pusieron en marcha el I Congreso Panamericano de Estudiantes, celebrado en Guatemala en 1921, como menciona Leticia González Sandoval en su artículo incluido en este dossier. 
líderes estudiantiles, Julio Antonio Mella, fue uno de los fundadores del partido comunista. En estos dos países las Universidades Populares que se crearon por iniciativa de los estudiantes jugaron un papel muy relevante por su participación en las luchas sociales y la confrontación con los regímenes autoritarios. En 1921 se crearon en el Perú las Universidades Populares González Prada, en cuyas actividades tuvo un destacado protagonismo, además de Haya de la Torre, el pensador marxista José Carlos Mariátegui ${ }^{28}$. En Cuba se fundó en 1923 la Universidad Popular José Martí, cuya breve trayectoria estudia Yoel Cordovíi ${ }^{29}$ en este dossier. Estas Universidades Populares son dos casos paradigmáticos de la involucración de las Universidades Populares en la arena política. También en el caso uruguayo, que estudia Gabriel Scagliola, las Universidades Populares se posicionaron contra la dictadura de Gabriel Terra, aunque no tuvieron la trascendencia política que estas desempeñaron en Perú o en Cuba. Estas confrontaciones políticas que protagonizaron muchas Universidades Populares dieron lugar a que en muchas ocasiones estas se desarrollaran por fuera de los marcos institucionales de la Universidad, o incluso contra la institucionalidad universitaria, como alternativas cuya puesta en práctica resultaba imposible dentro de la misma ${ }^{30}$.

\section{El devenir de las Universidades Populares}

Las Universidades Populares como las de Perú, Cuba o Uruguay, que se habían destacado por ser espacios de oposición política a gobiernos totalitarios, fueron objeto de persecución y fueron decayendo hacia finales de la década de 1920. La Universidad Popular Lastarria, que se había creado en la Universidad de Chile ya en 1918, pervivió hasta mediados de la década de $1930^{31}$. No obstante, otras Universidades Populares que no habían dependido del reformismo universitario permanecieron

28 Vid. Jeffrey L. Klaiber, "The Popular Universities and the Origins of Aprismo, 19211924", The Hispanic American Historical Review Vol. 55, No. 4 (1975): 693-715; Ariel Salcito, “Soñar y pensar sin limitaciones ni precio': la Nueva Generación peruana y la Universidad Popular González Prada”, Encuentro de Saberes No. 8 (2018): 11-21.

29 Yoel Cordoví Núñez, "La Universidad Popular José Martí en la órbita del pensamiento político de Julio Antonio Mella. Cuba, 1923-1927”, Historia Caribe Vol. XVI No. 38 (Enero-Junio 2021): 107136. DOI: https://doi.org/10.15648/hc.38.2021.2813

30 José Agustín Cano Menoni, "La extensión universitaria...", 16, nota 8.

31 Vid. Fabio Moraga Valle, 'Muchachos casi silvestres'. La Federación de Estudiantes y el movimiento estudiantil chileno, 1906-1936 (Santiago: Ediciones de la Universidad de Chile, 2007). 
activas, y surgieron otras nuevas que centraron su actividad en cubrir las necesidades de formación para el trabajo y el desempeño de oficios, a las que los sistemas de instrucción pública prácticamente no daban respuesta. Efectivamente, la enseñanza secundaria pública se había constituido en esta época en una vía para responder a las aspiraciones de los grupos sociales medios en ascenso, que aspiraban a acceder a la educación superior y a cubrir los requerimientos de la peculiar modernización que vivieron los países latinoamericanos en el periodo (empleos en la burocracia estatal, en el comercio de exportación, etc.), lo cual impidió la integración de las enseñanzas profesionales y de oficios en dicho nivel de enseñanza ${ }^{32}$.

Un caso paradigmático de este modelo de Universidad Popular es el que aborda Teresa Artieda ${ }^{33}$ en este dossier, describiendo la trayectoria de la Universidad Popular de la ciudad de Resistencia, en la provincia argentina del Chaco, creada en 1929. Este tipo de instituciones combinaron sus objetivos de enseñanza de oficios con otras actividades de difusión científica, extensión cultural y formación ciudadana, y en general funcionaron, como expresa Teresa Artieda, con modos de operar mucho más formalizados y de carácter ostensiblemente escolarizado. El desarrollo de este tipo de Universidades Populares en Argentina, tanto en Buenos Aires como en el interior del país, fue ciertamente amplio, uniéndose buena parte de ellas en una especie de federación denominada Universidades Populares Argentinas (UPA), que a partir de 1936 contó con un importante órgano de difusión, la Revista de las Universidades Populares Argentinas. En el artículo de Alejandro Yaverovski incluido en el dossier se ofrece una extensa lista de las Universidades Populares que funcionaban en el país a finales de la década de 1930. Un modelo similar de Universidad Popular, centrada en una enseñanza

32 Clara E. Núñez indica que muchos países latinoamericanos se enfrentaron a lo largo de la primera mitad del siglo XX a un aumento de la demanda de educación secundaria, cuando aún tenían un significativo atraso educativo y no habían completado la transición de la alfabetización, especialmente en el medio rural. Clara E. Núñez, "Educación y desarrollo económico en el continente americano", en La maldición divina. Ignorancia y atraso económico en perspectiva histórica, eds. C.E. Núñez y G. Tortella (Madrid: Alianza Universidad, 1993), 377.

33 Teresa Laura Artieda, "Historia de la Universidad Popular "Juan Ramón Lestani" (Chaco, Argentina, circa 1929-1960)", Historia Caribe Vol. XVI No. 38 (Enero-Junio 2021): 167-208 DOI: https://doi. org/10.15648/hc.38.2021.2816 
más formalizada de oficios, parece ser el de la Universidad Popular de Guatemala a partir de su nueva etapa que se inició en 1945.

La labor de educación popular llevada a cabo por las Universidades se canalizó en adelante sobre todo a través de la "extensión universitaria", que desde principios del siglo XX consiguió instalarse como una misión muy característica de la Universidad latinoamericana. Un buen ejemplo de ello fue la disolución de la Universidad Popular Mexicana en los programas de extensión universitaria impulsados a partir del rectorado de José Vasconcelos en la Universidad Nacional de México en 1920. No obstante, todavía en la década de 1930 se crearon algunas importantes Universidades Populares vinculadas al mundo universitario, como la Universidad Popular Alejandro Korn, fundada en la ciudad argentina de La Plata en 1937, la cual se caracterizó por ser un importante foco de difusión cultural y de debate político en el que participaron personalidades vinculadas a la Universidad y al Partido Socialista ${ }^{34}$.

\section{LA EXTENSIÓN AL MUNDO RURAL}

Durante la primera mitad del siglo XX en América Latina la educación en el medio rural presentaba una enorme desigualdad frente a la educación que había mejorado sensiblemente en las ciudades. Los países más urbanizados presentaban índices considerablemente más altos de alfabetización. A mediados del siglo la tasa media de alfabetización era del $64 \%$, siendo mayor el analfabetismo en los países con un elevado contingente de población indígena ${ }^{35}$. Por otra parte, en el medio rural la escolaridad primaria tenía una duración de tres o cuatro años, mientras por lo general la escuela primaria urbana constaba de seis años.

A pesar de esta situación tan desfavorable, las iniciativas de educación popular en el mundo rural no llegaron a tener la importancia ni la atención que estas tuvieron en las ciudades a través de las Universidades Populares, la extensión universitaria y la amplia variedad de experiencias creadas por organizaciones obreras, partidos políticos o instancias

34 Osvaldo Fabián Graciano, "Entre Cultura y Política: La Universidad Popular Alejandro Korn, 19371950", Trabajos y Comunicaciones No. 25 (1999).

35 Vid. Carlos Newland, "The Estado Docente and its Expansion: Spanish American Elementary Education, 1900-1950”, Journal of Latin American Studies, Vol. 26, Part 2 (1994): 449-467. 
oficiales. Como indicamos más arriba, fueron la Revolución Mexicana y algunas iniciativas inspiradas por el indigenismo las acciones más sobresalientes a favor de la educación popular en el campo.

Las "misiones" destinadas a mejorar la situación de la educación en el medio rural, que María García Alonso ${ }^{36}$ rastrea en su artículo incluido en este dossier, tuvieron un importante desarrollo en el caso del México postrevolucionario, experiencia que luego tendría su impacto en las Misiones Pedagógicas de la España de la Segunda República y en otros países de América Latina, en parte gracias a los propios misioneros españoles exilados en tierras americanas tras la Guerra Civil. La Misión Pedagógica Nacional que se organizó en Ecuador (1934), la Campaña de Cultura Aldeana en Colombia (1934), o las Misiones Socio-Pedagógicas del Uruguay (1945) son algunas de estas experiencias, en las que encontramos tanto iniciativas gubernamentales oficiales como la participación altruista de maestros, estudiantes normalistas y universitarios. Lamentablemente, el estudio de todas estas iniciativas y de las conexiones entre ellas, así como de la educación rural en general en la primera mitad del siglo XX, son temas que tienen todavía un reducido desarrollo historiográfico en América Latina ${ }^{37}$.

En su artículo María García Alonso establece importantes vinculaciones entre el concepto de "misión", que adoptan muchas de las experiencias de extensión dirigidas al mundo rural, con la idea cristiana de "evangelización" y, en definitiva, con la difusión de un proyecto civilizatorio. Esta concepción de la extensión sería cuestionada a principios de los años 1960 por el brasileño Paulo Freire, en su afán por crear una pedagogía de la liberación para los campesinos latinoamericanos. Para Freire "la expresión 'extensión educativa' solo tiene sentido si se toma la educación como una práctica de 'domesticación'. Educar y educarse en la práctica de la libertad, no es extender algo desde la 'sede del saber'

36 García Alonso, María. "La extensión pedagógica en Iberoamérica como modelo de acción política: las misiones educativas laica”, Historia Caribe Vol. XVI No. 38 (Enero-Junio 2021): 209-235. DOI: https://doi.org/10.15648/hc.38.2021.2819

37 Véanse, entre otros, Alicia Civera Cerecedo, Juan Alfonseca Giner de los Ríos y Carlos Escalante Fernández (coords.), Campesinos y escolares: La construcción de la escuela en el campo latinoamericano, siglos XIX y XX (México: Miguel Ángel Porrúa/El Colegio Mexiquense, 2011); Pilar Gonzalbo (coord.) y Gabriela Ossenbach (colab.), Educación rural e indígena en Iberoamérica (México/ Madrid: El Colegio de México/UNED, 1996). 
a la 'sede de la ignorancia' para 'salvar' con este saber a los que habitan en ella" 38 . Como afirma Ricardo Nassif, la pedagogía de Freire sería una de las primeras pedagogías que buscaría su coherencia en el intento de constituirse desde y con los oprimidos, antes que para ellos ${ }^{39}$.

\section{A MODO DE CIERRE: UN PROGRAMA DE INVESTIGACIÓN PENDIENTE}

Dejamos planteado aquí un amplio programa de investigación sobre las Universidades Populares y las experiencias de extensión y educación popular en América Latina en el primer tercio del siglo XX, que necesariamente debería tener una mirada transnacional y tomar en cuenta las "redes intelectuales y textuales" 40 que propiciaron su génesis y desenvolvimiento, así como los diversos modelos que les sirvieron de referencia para su creación. Hacen falta muchos estudios sobre otras Universidades Populares de distintos países del continente que no hemos podido incorporar en este dossier ni tener en cuenta en este estudio introductorio. La problematización que introduce Paulo Freire acerca de los procesos de extensión pedagógica invita también a introducir nuevas preguntas en el estudio de esta temática.

Al avance de este programa de investigación pretendemos que contribuya modestamente este dossier que la revista Historia Caribe nos ha dado la oportunidad de coordinar. Confiamos en que la elaboración de algunos criterios para la periodización y la categorización de estas experiencias, que hemos procurado en estas páginas, puedan resultar útiles para dicho fin. Sabemos que el acceso a las fuentes para una investigación de estas características no resulta ciertamente sencillo, como muestran algunos de los trabajos incluidos en el dossier, pues por el

38 Paulo Freire, ¿Extensión o comunicación? La concientización en el medio rural (México: Siglo XXI, 1978), 25 (la edición original en portugués es de 1969).

39 Ricardo Nassif, "Las tendencias pedagógicas en América Latina (1960-1980)", en El sistema educativo en América Latina, eds. Ricardo Nassif, Germán W. Rama y Juan Carlos Tedesco (Buenos Aires: UNESCO / CEPAL / PNUD / Kapelusz, 1984) 61 (las cursivas son nuestras). Este cuestionamiento que hace Freire a la "extensión" no fue del todo ajeno a los promotores de la extensión universitaria a principios del siglo XX. Como nos llama la atención Cano Menoni, ya en el Manifiesto del Centro de Estudiantes de Derecho de la Universidad de Buenos Aires, al inaugurarse los cursos de extensión universitaria en 1920, los estudiantes declararon: "No queremos conducir. Queremos que cada uno tenga capacidad para concurrir con esfuerzo consciente a preparar el resurgimiento fecundo y dinámico de la humanidad reconciliada". José Agustín Cano Menoni, "La extensión universitaria...", 17 y Dardo Cúneo, La Reforma Universitaria..., 25.

40 Tomamos esta expresión de Liliana Weinberg, "Redes intelectuales y redes textuales...". 
carácter informal o la reducida duración en el tiempo de numerosas Universidades Populares y otras experiencias de extensión, en muchos casos no se cuenta con archivos organizados. La necesidad de acudir a informaciones de prensa o a las innumerables revistas que se editaron en torno a las organizaciones estudiantiles (algunas de ellas también de existencia efímera), a veces de difícil acceso, es un obstáculo para documentar la trayectoria de estas instituciones ${ }^{41}$.

Gabriela Ossenbach
Editora Invitada
Universidad Nacional de Educación a Distancia-UNED (España)
Gabriel Scagliola
Editor Invitado
Museo Pedagógico de Montevideo (Uruguay)

DOI: https://doi.org/10.15648/hc.38.2021.2808

\section{BibLIOGRAFÍA}

Bergel, Martín (coord.). Los viajes latinoamericanos de la reforma universitaria. Rosario: Humanidades y Artes Ediciones, 2018.

Cano Menoni, José Agustín. "La extensión universitaria en la transformación de la Universidad latinoamericana del siglo XXI: disputas

41 La progresiva digitalización de muchas de estas fuentes y su acceso libre a través de Internet están facilitando la investigación en este campo. Revistas como Repertorio Americano [https://repositorio.una. ac.cr/handle/11056/2923] o Amauta [https://digital.iai.spk-berlin.de/viewer/toc/812949153/0/ LOG_0000/], así como muchas de las revistas de las asociaciones estudiantiles de la época, están ya disponibles en ese formato. Véanse, entre otras, la biblioteca virtual "Las revistas estudiantiles y la Reforma Universitaria (1908-1928)" del Centro de Documentación e Investigación de la Cultura de Izquierdas (Buenos Aires)

[http://exhibiciones.cedinci.org/exhibits/show/reforma_universitaria/revistas], el portal "Memoria Chilena" de la Biblioteca Nacional de Chile [http://www.memoriachilena.gob.cl], o el portal de "Publicaciones Periódicas del Uruguay" de la Universidad de la República (Montevideo) [https:// anaforas.fic.edu.uy/jspui/handle/123456789/13].

No podemos dejar de mencionar la labor de recopilación de fuentes sobre las Misiones Socio-Pedagógicas del Uruguay que llevaron a cabo María García Alonso y Gabriel Scagliola, que se reunieron primero en una exposición en el Museo Pedagógico de Montevideo en 2009, y más tarde en la edición de un extenso volumen que reúne documentos, artículos de prensa, fotografías y testimonios sobre aquella experiencia de extensión pedagógica al mundo rural. María García Alonso (ed.) y Gabriel Scagliola (coord.), Misiones Socio-Pedagógicas de Uruguay (1945-1971). Documentos para la memoria (Montevideo: Consejo de Formación en Educación, ANEP, 2012). 
y desafíos" (Documento de Trabajo). Buenos Aires: CLACSO, 2014.

Carli, Sandra. Niñez, pedagogía y política. Transformaciones de los discursos acerca de la infancia en la historia de la educación argentina entre 1880 y 1955. Buenos Aires: Universidad de Buenos Aires / Ed. Miño y Dávila, 2002.

Civera Cerecedo, Alicia, Juan Alfonseca Giner de los Ríos y Carlos Escalante Fernández (coords.). Campesinos y escolares: La construcción de la escuela en el campo latinoamericano, siglos XIX y XX. México: Miguel Ángel Porrúa/El Colegio Mexiquense, 2011. Cruz, Vladimir de la. Las luchas sociales en Costa Rica, 1870-1930. San José: Editorial de la Universidad de Costa Rica, 2004.

Cúneo, Dardo. La Reforma Universitaria, 1918-1930. Caracas: Biblioteca Ayacucho, 1978.

Fernández Rueda, Sonia. La escuela que redime. Maestros, infancia escolarizada y pedagogía en Ecuador, 1925-1948. Quito: Corporación Editorial Nacional, 2018.

Freire, Paulo. ¿Extensión o comunicación? La concientización en el medio rural. México: Siglo XXI, 1978.

García Alonso, María (ed.) y Gabriel Scagliola (coord.). Misiones Socio-Pedagógicas de Uruguay (1945-1971). Documentos para la memoria. Montevideo: Consejo de Formación en Educación, ANEP, 2012.

Gonzalbo, Pilar (coord.) y Gabriela Ossenbach (colab.). Educación rural e indígena en Iberoamérica. México/Madrid: El Colegio de México/UNED, 1996.

Graciano, Osvaldo Fabián. "Entre Cultura y Política: La Universidad Popular Alejandro Korn, 1937-1950”. Trabajos y Comunicaciones No. 25 (1999): 71-119.

Guereña, Jean-Louis y Alejandro Tiana. “La educación popular”. En Historia de la Educación en la España Contemporánea. Diez años de investigación, editado por Jean-Louis Guereña, Julio Ruiz Berrío y Alejandro Tiana Ferrer. Madrid: Centro de Publicaciones del Ministerio de Educación y Ciencia, C.I.D.E., 1994, 141-171.

Klaiber, Jeffrey L. "The Popular Universities and the Origins of Aprismo, 1921-1924". The Hispanic American Historical Review Vol. 55, No. 4 (1975): 693-715. 
Llaguno Thomas, José Julián. La semilla que germina. Anarquismo, cultura política y nueva intelectualidad en Costa Rica, 1900-1914. San José: Acracia Editores, 2012.

Lucía, Daniel Omar de. "La tradición laica en la 'ciudad universitaria'. El movimiento librepensador en La Plata, 1896-1916”. En La Universidad de La Plata y el movimiento estudiantil, desde sus orígenes hasta 1930, compilado por Hugo Biagini. La Plata: Editorial de la Universidad Nacional de La Plata, 2001, 13-26.

Mazo, Gabriel del (comp.). La Reforma Universitaria. Buenos Aires: Federación Universitaria de Buenos Aires, 1926-1927, 6 vols.

Mazo, Gabriel del (comp.). La Reforma Universitaria. La Plata: Centro de Estudiantes de Ingeniería, 1941, 3 vols.

Melgar Bao, Ricardo. "Las Universidades Populares en América Latina, 1910-1925”. Estudios. Revista del Centro de Estudios Avanzados (Universidad Nacional de Córdoba) No. 11-12 (1999): 41-57.

Moraga Valle, Fabio. 'Muchachos casi silvestres'. La Federación de Estudiantes y el movimiento estudiantil chileno, 1906-1936. Santiago: Ediciones de la Universidad de Chile, 2007.

Moraga Valle, Fabio. "Reforma desde el sur, revolución desde el norte. El Primer Congreso Internacional de Estudiantes de 1921". Estudios de Historia Moderna y Contemporánea de México No. 47 (2014): 155-195.

Nassif, Ricardo. "Las tendencias pedagógicas en América Latina (19601980)". En El sistema educativo en América Latina, editado por Ricardo Nassif, Germán W. Rama y Juan Carlos Tedesco. Buenos Aires: UNESCO / CEPAL /PNUD / Kapelusz, 1984, 51-102.

Newland, Carlos. "The Estado Docente and its Expansion: Spanish American Elementary Education, 1900-1950”. Journal of Latin American Studies, Vol. 26, Part 2 (1994): 449-467.

Núñez, Clara E. "Educación y desarrollo económico en el continente americano”. En La maldición divina. Ignorancia y atraso económico en perspectiva histórica, editado por Clara E. Núñez y Gabriel Tortella. Madrid: Alianza Universidad, 1993, 359-380.

32 Pineo, Ronn F. y James A. Baer (eds.). Cities of Hope. People, Protests and Progress in Urbanizing Latin America, 1870-1930. Boulder, Colorado / Oxford: Westview Press, 1998. 
Pita González, Alexandra (comp.). Redes intelectuales transnacionales en América Latina durante la entreguerra. México: Universidad de Colima y Miguel Ángel Porrúa, 2016.

Portantiero, Juan Carlos. Estudiantes y política en América Latina. El proceso de la Reforma Universitaria, 1918-1938. México: Siglo XXI, 1978.

Prado, Gustavo H. "El compromiso de Rafael Altamira con la extensión universitaria ovetense y su difusión en América". Canelobre: Revista del Instituto Alicantino de Cultura Juan Gil-Albert No. 59 (2012): 80-91.

Prado, Gustavo H. Rafael Altamira en América (1909-1910). Historia e historiografía del proyecto americanista de la Universidad de Oviedo. Madrid: Consejo Superior de Investigaciones Científicas, 2008.

Rinesi, Eduardo. "Prólogo". En Estudiantes y Política en América Latina. El proceso de la Reforma Universitaria, 1918-1938, por Juan Carlos Portantiero. Buenos Aires, Ed. de la Facultad de Filosofía y Letras de la UBA, 2018, 7-24.

Sáenz Obregón, Javier et al. Mirar la infancia: pedagogía, moral y modernidad en Colombia, 1903-1946. Medellín: Colciencias / Eds. Foro Nacional por Colombia / Eds. Uniandes / Ed. Universidad de Antioquia, 1997, 2 vols.

Salcito, Ariel. “'Soñar y pensar sin limitaciones ni precio’: la Nueva Generación peruana y la Universidad Popular González Prada”. Encuentro de Saberes No. 8 (2018): 11-21.

Torres Aguilar, Morelos. Cultura y Revolución. La Universidad Popular Mexicana. México: UNAM, 2010.

Tünnermann, Carlos. "La reforma universitaria de Córdoba". Educación Superior y Sociedad, Vol. 9, No. 1 (1998): 103-127.

Van Aken, Mark. "University Reform before Córdoba”. The Hispanic American Historical Review Vol. 51 No. 3 (1971): 447-462.

Weinberg, Gregorio. Tiempo, destiempo y contratiempo. Buenos Aires: Ed. Leviatán, 1993.

Weinberg, Liliana. "Pedro Henríquez Ureña y las ideas de la Reforma Universitaria: tesis sobre la Universidad". Cuadernos Americanos No. 167 (2019): 71-101. 
Weinberg, Liliana. "Redes intelectuales y redes textuales: las revistas del Reformismo Universitario", Revista de Historia de América No. 158 (2020): 191-221.

Yaverovski, Alejandro Martín. "Cien años de oscuridad sobre las Universidades Populares: a cien años del chispazo de la Reforma Universitaria en Córdoba". Encuentro de Saberes No. 8 (2018): 23-27.

Yaverovski, Alejandro Martín. "Universidades Populares: la búsqueda de la genealogía propia”, De Signos y Sentidos. Revista de la Universidad Nacional del Litoral No. 19 (2018): 29-49. 